\title{
CENTRAIS SINDICAIS E ATITUDES DEMOCRÁTICAS ${ }^{1}$
}

\author{
ADALBERTO M. CARDOSO \\ ALVARO A. COMIN
}

\begin{abstract}
Num período relativamente curto (1978-1983) e marcado por intensa mobilização sindical e particularmente grevista, o Brasil viu surgirem duas tendências bem marcadas de ação sindical, consubstanciadas, a partir de 1983, em duas centrais sindicais de abrangência nacional: a Central Única dos Trabalhadores (CUT) e a Coordenação Nacional da Classe Trabalhadora (Conclat), mais tarde tornada Central Geral dos Trabalhadores (CGT). A partir de estratégias e orientações político-sindicais distintas, essas duas correntes passaram a reivindicar e a disputar entre si a condição de representantes dos trabalhadores frente ao Estado, ao sistema político e ao patronato ${ }^{2}$.
\end{abstract}

${ }^{1}$ Esse trabalho resume os principais resultados da pesquisa "Padrōes de representação sindical e democracia no Brasil: um survey entre trabalhadores", financiada pela Fapesp. Esse survey foi longamente fermentado em uma série de reuniōes no Grupo de Estudos Políticos, núcleo que se constituiu no Cebrap sob coordenação de Guillermo O'Donnell e Vilmar Faria entre 1987 e 1994. Daquelas reuniões tomaram parte, além dos coordenadores, os professores Fabio Wanderley Reis e Antônio Augusto Prates, da UFMG, que montaram e aplicaram questionário análogo junto a públicos diversos dos analisados aqui. Participou também José Ramón Montero, então professor da Universidad Complutense de Madrid, na qualidade de especialista em surveys em transições do autoritarismo. Nas reuniões de grupo estiveram presentes ainda, em maior ou menor intensidade, Sebastião Velasco e Cruz, da Universidade de Campinas, Jorge Avelino Filho, e Carlos A. M. Novaes, Adalberto M. Cardoso e Alvaro A. Comin, do Cebrap. Esses três últimos pesquisadores foram os responsáveis pela forma final assumida pelo questionário, aplicado entre maio e agosto de 1994 e já sob coordenação de Francisco de Oliveira (Cebrap) e Reginaldo Prandi (LAB/USP). O Datafolha foi o responsável pelo campo, supervisionado pelos autores desse artigo. A SPSS Inc. agradecemos a cessão gratuita do processador SPSS for Windows versão 5.0 , com o qual foram trabalhados os dados usados neste artigo. Aproveitamos para agradecer a todos, eximindo-os, obviamente, dos equívocos que aqui por ventura permaneçam.

2 É verdade que a Conclat, posteriormente CGT, terminaria por fragmentar-se em outras instituições, sempre por oposição à CUT. Mas o que importa marcar é que, já em inícios dos anos 
Em meio a uma transição política (e sobre isto há relativo consenso na literatura) de cujo processo de pactação estiveram excluídos os segmentos mais organizados dos trabalhadores, o surgimento e a eventual consolidação de organismos capazes de, num plano mais agregado, vocalizar e representar esses interesses apresentava-se como algo auspicioso. A "correção" na rota conservadora já percorrida durante a transição brasileira (que deveria corresponder não apenas à incorporação de demandas mas, e talvez sobretudo, à construção de canais institucionais de participação política dos trabalhadores), poderia estar encontrando meios para se viabilizar através das próprias inovações institucionais que o movimento sindical vinha forjando, para além dos limites desenhados pela normatividade corporativa que sobrevivera a mais uma mudança de regime político.

Entretanto, não é de todo incontestado o caráter inovador das centrais sindicais, se do que se trata é refletir sobre a construção de instituições democráticas de vocalização de interesses dos trabalhadores no Brasil. Como observou Leôncio Martins Rodrigues, as centrais sindicais surgidas nos anos 1980 são essencialmente fruto da sobreposição a uma estrutura institucional preexistente, qual seja, a estrutura sindical oficial, construída durante a primeira passagem de Vargas pelo poder nos anos 1930-40 (Martins Rodrigues, 1989). As atuais centrais sindicais seriam, assim, uma espécie de aberração institucional, uma vez que sua própria existência significaria, em alguma medida, uma cunha encravada na estrutura oficial, da qual, no entanto, elas se nutriram desde o princípio.

Essas não são abordagens necessariamente polares no debate acadêmico brasileiro atual. Elas expressam, na verdade, a tensão clássica entre renovação e permanência em processos transitórios, isto é, remetem a vetores de mudança que, nascidos das entranhas da ordem anterior, apresentam potencialidades de renovação em parte informadas por aquela ordem, em parte por projetos nem sempre explícitos de sua superação. Esse trabalho argui justamente essa clivagem, problematizando o processo de consolidação das centrais sindicais no quadro mais geral de renovação do horizonte das relações de classe no Brasil pós-autoritário. Interessa-nos perscrutar em que medida as centrais foram capazes de se consolidar como organizações de interesse que, ainda que internas ou, no mínimo, justapostas à "ordem regulada" (Santos, 1979), instituíram-se em alternativa real

1990, a oposição entre as duas tendências emersas nos anos 1980 volta a expressar-se em duas centrais sindicais predominantes, CUT e Força Sindical.Ver Martins Rodrigues (1991) e (1990); Tavares de Almeida (1992). Para caracterizaçōes das centrais sindicais, ver Martins Rodrigues e Cardoso (1993); Comin (1995); Rodrigues (1996); Cardoso, Lopes, Comin e Piva (1994). 
de representação dos trabalhadores na democracia emergente, alternativa capaz, inclusive, de romper com os limites estreitos daquela ordem. É esse o problema que nos move.

Ponto culminante de um projeto mais amplo de pesquisa que já rendeu muitos frutos ${ }^{3}$, esse trabalho tenta operacionalizar esse problema por um ângulo jamais explorado pela literatura, isto é, perguntando pela capacidade das centrais sindicais se instituírem em centros efetivos de constituição de identidades sindical e política, de tal modo a servir de fato de mediadoras da constituição das preferências e atitudes daqueles que elas dizem representar. Por outros termos, trata-se de avaliar a capacidade de penetração do discurso e da prática das centrais em suas bases de sustentação, essa capacidade emergindo como um momento crucial de sua consolidação no cenário sindical brasileiro.

Essa formulação denota uma aposta normativa na institucionalização das relações sociais como elementos virtuosos da construção democrática, na eventualidade de que as instituições se constituam como práticas reiteradas, estruturadas e eventualmente formalizadas que: alarguem os horizontes temporais de cálculo estratégico de seus membros, ao reduzir a incerteza das transações cotidianas e ao planejar a utilização dos recursos coletivos; operem como centros produtores e reprodutores de identidade ao agregar, organizar e vocalizar o interesse de seus membros ${ }^{4}$; e, enquanto instituições representativas, não apenas tomem o lugar dos represèntados, agindo em seu nome, como também logrem nuclear os processos de validação das regras da interlocução com os agentes portadores de interesses divergentes, estruturando por sua vez a interlocução mesma segundo a lógica do reconhecimento da legitimidade do oponente na integridade de seus direitos e interesses. Nesse recorte, se há uma aposta normativa na "virtuosidade" das instituições, trata-se de validar ou não uma aposta nas centrais sindicais enquanto possíveis instrumentos da renovação da contratualidade de classe no Brasil, por meio da análise da natureza de sua representatividade, medida por sua capacidade de instruir a constituição de atitudes e práticas dos representados, de um lado e, de outro lado, de fazê-lo num sentido que aprofunde as bases da convivência democrática no Brasil.

A operacionalização empírica desse recorte analítico será feita com base num survey realizado junto a quatro categorias profissionais da

\footnotetext{
${ }^{3}$ Dentre os trabalho resultantes estão Cardoso (1992 e 1995); Comin (1994 e 1995); Cardoso e Comin (1995); Martins Rodrigues e Cardoso (1993); e Oliveira e Prandi coords (1996), sendo este último o relatório final de pesquisa que serve de base a este artigo.

4 Ver, dentre outros, Douglas (1979).
} 
grande São Paulo. Levando em consideração que, no cenário atual brasileiro, estão consolidadas pelo menos duas centrais sindicais (CUT e Força Sindical) com perfis programáticos e ideológicos relativamente bem definidos, impõe-se como abordagem estratégica (e inovadora) investigar em que medida tais orientações instauram clivagens relevantes nas bases sindicais e estabelecer a natureza dessas clivagens em termos da consolidação de atitudes e práticas prenhes de "virtualidades institucionais" democráticas. A tarefa não é simples, e não estamos certos de ter chegado a bom termo. Nos daremos por satisfeitos se esse texto suscitar um debate qualificado em torno das questões que propõe, contribuindo ele também para a renovação dos horizontes analíticos sobre as modalidades de incorporação dos trabalhadores na sociedade brasileira pós-autoritária.

$\mathrm{O}$ artigo divide-se em três partes. Na primeira, descrevemos as centrais sindicais em termos da abrangência de sua penetração na estrutura sindical e das características básicas dos sindicatos que as sustentam. $\mathrm{Na}$ segunda, analisamos o survey, atentos à problemática global esboçada aqui e a algums hipóteses secundárias formuladas ao início de cada uma das seções. Interessa-nos, antes de tudo, avaliar o impacto da preferência pelas centrais nas atitudes e práticas políticas e sindicais dos trabalhadores. Finalmente, concluímos com um resumo dos achados empíricos e tentamos extrair disso consequências em termos da consolidação institucional democrática.

\section{AS CENTRAIS SINDICAIS EM NÚMEROS}

Ainda que o survey seja o foco maior de análise, é mister uma rápida descrição das centrais sindicais estudas. A Tabela 1 nos traz dados censitários para o ano de 1991, únicos confiáveis dada a diversidade e precariedade das informaçōes disponíveis na literatura ou mesmo nas próprias centrais ${ }^{5}$. Indo direto ao que interessa, é marcante a diversidade do perfil das três centrais sindicais mais importantes (CUT, Força Sindi-

5 Comin (1995) mostra que os dados oficiais da CUT são muito próximos daqueles encontrados pelo IBGE em sua pesquisa anual, mas o mesmo não ocorre com as CGT's. Sobre a Força Sindical, até a publicação da referida pesquisa os únicos dados existentes eram encontrados em Martins Rodrigues e Cardoso (1993). Logo, seria muito temerário utilizar dados fornecidos por cada central. O preço a se pagar ao utilizar dados referentes ao início dos anos 1990 é a perda dos movimentos de constituição de sindicatos ocorrido a partir de 1991 , que terāo, eventualmente, mudado o panorama da representaçāo das centrais. A vantagem, do nosso ponto de vista, é que podemos contar com uma fonte confiável e homogênea. As tabulações analisadas aqui são fruto de manipulação por nós da base de micro-dados do IBGE. São, portanto, originais. 
cal e $\mathrm{CGT}^{6}$ ) em termos do tipo de sindicato filiado e da penetração geográfica e econômica de cada uma. Enquanto a Força Sindical era quase exclusivamente uma central de sindicatos de empregados urbanos, a CUT trazia em suas hostes $1 / 3$ de sindicatos de trabalhadores rurais. A CGT, embora menor que suas concorrentes, também tinha porcentagem não desprezível de sindicatos rurais entre seus filiados (um quinto), e era maior a presença de sindicatos de agentes autônomos em geral na CGT do que nas demais.

$\mathrm{Na}$ verdade, a CUT era uma central "representativa" da distribuição global por região, ramo e segundo o tipo de sindicato e, nesse sentido, pode-se dizer que espelhava a distribuição da população de sindicatos, mostrando capacidade de penetração em todos os ramos da economia, em todas as regiōes do país. Isso fazia da CUT uma central sindical de amplo espectro, nacionalmente consolidada. Já a Força Sindical, em que pese ter sido fundada no ano de realização da pesquisa, era uma central sindical urbana e concentrada, tendo suas bases no Sudeste e no Sul do Brasil. Além disso, era predominantemente de indústria. A tabela não mostra, mas os sindicatos de trabalhadores em indústrias metalúrgicas (15\%) e de alimentação (18\%) forneciam um terço dos filiados à Força Sindical em 1991. Além de ser uma central de indústria, concentrava-se em setores bem demarcados nesse ramo da economia. Finalmente, a CGT também tinha um perfil nacional, mas distante da média da população de sindicatos. Parece claro que trajetórias diversas de emergência e consolidação das centrais se consubstanciaram em perfis bastante distintos, com a Força Sindical e a CGT tendendo à especialização e a CUT tendendo a um perfil de amplo espectro.

Esse retrato panorâmico esconde semelhanças e diferenças organizacionais por vezes surpreendentes. No campo das confirmações de expectativas, a análise da Tabela 2 permite afirmar, de um modo geral (mas em menor intensidade para a CGT), que os sindicatos filiados a alguma das três centrais eram maiores do que os não filiados: suas bases territoriais eram em média maiores, tinham número maior de associados e um número maior desses últimos estava em condições de votar em 1991 (ítens 2 a 4 da Tabela 2). Entretanto, se atentarmos para a distribuição média das fontes de financiamento, por exemplo, as diferenças já não são tão bem marcadas (ítens 9 a 12). Os sindicatos da CUT e da CGT tinham a participação média das contribuições associativas na receita total bastante próxima dos outros sindicatos não filiados a centrais (em torno de me-

6 Embora a CGT não tenha sido objeto do survey, boa parte de seus quadros iria compor a Força Sindical nos anos 1990. Por isso interessa analisá-la, ainda que rapidamente. 
TABELA 1 - Indicadores selecionados de consolidação das centrais sindicais

\begin{tabular}{|c|c|c|c|c|}
\hline \multirow[b]{2}{*}{ Indicadores selecionados } & \multicolumn{3}{|c|}{ Centrais sindicais } & \multirow[t]{2}{*}{ Total $\left({ }^{*}\right)$} \\
\hline & CUT & $\begin{array}{l}\text { Força } \\
\text { Sindical }\end{array}$ & $\begin{array}{c}\text { CGT } \\
\text { (central) }\end{array}$ & \\
\hline \multicolumn{5}{|l|}{ Tipo de sindicato } \\
\hline $\begin{array}{l}\text { Agentes Autônomos } \\
\text { Empregados urbanos } \\
\text { Profissionais liberais } \\
\text { Trabalhadores autônomos } \\
\text { Trabalhadores avulsos } \\
\text { Trabalhadores rurais }\end{array}$ & $\begin{array}{r}0,0 \\
55,2 \\
4,6 \\
0,4 \\
0,1 \\
39,6\end{array}$ & $\begin{array}{r}0,0 \\
90,6 \\
0,5 \\
2,4 \\
0,5 \\
6,1\end{array}$ & $\begin{array}{r}0,0 \\
67,7 \\
1,9 \\
4,3 \\
4,3 \\
21,7\end{array}$ & $\begin{array}{r}5,2 \\
43,3 \\
5,4 \\
1,5 \\
4,1 \\
40,5\end{array}$ \\
\hline \multicolumn{5}{|l|}{ Região do pais } \\
\hline $\begin{array}{l}\text { Norte } \\
\text { Nordeste } \\
\text { Sudeste } \\
\text { Sul } \\
\text { Centro Oeste }\end{array}$ & $\begin{array}{r}9,8 \\
30,5 \\
30,5 \\
20,8 \\
8,4\end{array}$ & $\begin{array}{r}10,8 \\
6,6 \\
53,3 \\
20,3 \\
9,0\end{array}$ & $\begin{array}{r}14,9 \\
31,7 \\
31,7 \\
13,7 \\
8,1\end{array}$ & $\begin{array}{r}4,5 \\
28,4 \\
30,6 \\
29,2 \\
7,3\end{array}$ \\
\hline \multicolumn{5}{|l|}{ Ramo } \\
\hline $\begin{array}{l}\text { Indústria } \\
\text { Comércio } \\
\text { Serviços } \\
\text { Finanças } \\
\text { Ensino } \\
\text { Prof. Liberais } \\
\text { Rurais } \\
\text { Serviço Público } \\
\text { Outros }\end{array}$ & $\begin{array}{r}24,0 \\
7,0 \\
9,6 \\
4,5 \\
3,7 \\
4,6 \\
39,3 \\
5,8 \\
1,5\end{array}$ & $\begin{array}{r}51,7 \\
15,1 \\
16,6 \\
3,8 \\
0,5 \\
0,5 \\
6,1 \\
2,8 \\
2,9\end{array}$ & $\begin{array}{r}38,5 \\
9,4 \\
22,9 \\
0,6 \\
0,6 \\
1,9 \\
21,7 \\
2,5 \\
1,9\end{array}$ & $\begin{array}{r}18,9 \\
9,7 \\
14,6 \\
2,4 \\
1,7 \\
5,4 \\
40,5 \\
5,3 \\
1,7\end{array}$ \\
\hline$N$ & 1526 & 212 & 167 & 5581 \\
\hline
\end{tabular}

Fonte: Pesquisa Sindical IBGE - 1991, tabulações especiais

${ }^{*}$ ) Total de sindicatos de trabalhodores rurais e urbanos

tade). O mesmo não ocorria com os sindicatos da Força Sindical, cuja importância da contribuição assistencial era elevada em termos comparativos, e os associados eram responsáveis, em média, por menos de $1 / 3$ da receita dos sindicatos dessa central. Vale a pena marcar, também, que o imposto sindical era muito menos importante como fonte de recursos do que imaginam o senso comum e mesmo importantes analistas do sindicalismo brasileiro ${ }^{7}$. Isso vale, em termos médios, para todos os sindicatos

7 Por exemplo, Martins Rodrigues (1990 e 1991) e Pochmann (1996). 
com exceção dos filiados à CGT, que apresentam $1 / 3$ de sua receita composta pela fonte compulsória.

Ainda no campo das confirmações de expectativas, os sindicatos filiados a alguma central são mais enraizados em suas categorias do que os outros, se bem que, em termos médios, a presença de delegados sindicais e de membros de comissão de fábrica nos primeiros esteja aquém do que se poderia esperar, principalmente nos sindicatos cutistas. Isso porque parte importante da novidade do sindicalismo que desembocou na CUT foi justamente $o$ direcionamento da atenção para os chãos fábrica e a luta por constituição de organizações por locais de trabalho $(\mathrm{OLT})^{8}$. Mas os itens 6 a 8 da Tabela 2 mostram que esse intuito ainda não se efetivara em 1991. Assim, se CUT, CGT e Força Sindical tinham sindicatos com maiores médias de OLT do que sindicatos não filiados a centrais sindicais; se entre os filiados a centrais, a CUT apresentava melhores índices que as demais, exceto no ítem "delegado sindical", cuja média era um pouco inferior à dos sindicatos forcistas; ainda assim as médias eram muito baixas de maneira geral, sugerindo que mesmo os sindicatos cutistas tinham penetrado pouco em suas bases.

Se atentarmos às diferenças entre as centrais sindicais, chama a atenção o fato de que a CUT, como era de se esperar, era uma central de sindicatos "jovens", por oposição à CGT e à Força Sindical (item 1 da Tabela 2). A média aparentemente não tão diferente entre as centrais esconde o fato de que, entre os sindicatos cutistas, metade foi criada a partir de 1976. Na verdade, a tabela não mostra, mas segundo a mesma fonte cerca de $1 / 3$ de todos os sindicatos de trabalhadores urbanos criados entre 1983 e 1988 eram filiados à CUT em $1991^{9}$. Por outras palavras, a CUT era fortemente uma central de novos sindicatos, criados sob sua coordenação a partir do ano de sua fundação. Já a CGT e a Força Sindical eram centrais de sindicatos consolidados antes do ressurgimento do sindicalismo no pós-1964. Metade dos sindicatos forcistas foi fundada até 1968 , e metade dos cegetistas já existia em 1971. Essas duas centrais, mais do que a CUT, devem suas raízes a sindicatos "velhos", com larga tradição organizativa nos limites da estrutura sindical corporativa .

Esses dados corroboram expectativas. No campo das surpresas estão as estratégias negociais equivalentes de sindicatos cutistas, forcistas e cegetistas. A história da consolidação das centrais sindicais permitia esperar dos sindicatos da CUT menor taxa de recurso à Justiça do Trabalho (JT) do que os sindicatos das outras duas centrais. O discurso e a prática daquela sempre valorizaram a autonomia das organizações de interesse em

8 Rodrigues (1990); Tavares de Almeida (1983).

9 Ver Cardoso coord (1997: Cap. I). 
relação ao Estado. Alguns de seus sindicatos mais importantes, como os metalúrgicos do $\mathrm{ABC}$ e os bancários da capital, celebraram acordos formais ou informais de não recurso à $\mathrm{JT}$ com sindicatos patronais já no final dos anos 1980. Apesar disso, os sindicatos da CUT realizavam, em média, tantas negociações via JT quanto seus pares de outras centrais. Isso é um indicador importante da capacidade reduzida que a CUT vem apresentando de vincular seus sindicatos ao seu discurso programático.

Em suma, e atendo-nos às centrais analisadas daqui por diante, os dados para 1991 revelam diferenças e semelhanças bem marcadas entre

TABELA 2 - Médias de alguns indicadores selecionados de perfil dos sindicatos segundo a central sindical a que se filiavam - Brasil, 1991 (exclui sindicatos de empregadores)

\begin{tabular}{|c|c|c|c|c|c|}
\hline \multirow[b]{2}{*}{ Indicadores } & \multicolumn{4}{|c|}{ Central de filiação } & \multirow{2}{*}{ Total } \\
\hline & $\begin{array}{c}\text { Nenhum } \\
\text { USI } \\
\text { ConfGT }\end{array}$ & CUT & $\begin{array}{l}\text { Força } \\
\text { Sindical }\end{array}$ & $\begin{array}{c}\text { CGT } \\
\text { (Central) }\end{array}$ & \\
\hline 1. Idade do sindicato & 21,1 & 19,5 & 23,0 & 24,8 & 20,9 \\
\hline 2. Pessoas na base territorial & 4517,1 & 7225,0 & 13779,5 & 7093,9 & 5382,6 \\
\hline 3. Número de associados & 1849,4 & 2737,9 & 4166,6 & 2722,5 & 2113,4 \\
\hline 4. Sócios em condiçōes de votar & 192,2 & 418,0 & 348,3 & 197,6 & 242,4 \\
\hline 5. Total de diretores & 15,1 & 20,0 & 19,0 & 16,2 & 16,2 \\
\hline $\begin{array}{l}\text { 6. Quantos delegados estáveis? } \\
\text { 7. Número de comissões de fábrica }\end{array}$ & 1,7 & 4,7 & 4,8 & 2,7 & 2,4 \\
\hline $\begin{array}{l}\text { por sindicato } \\
\text { 8. Integrantes da comissão com }\end{array}$ & 0,1 & 0,3 & 0,3 & 0,2 & 0,2 \\
\hline $\begin{array}{l}\text { estabilidade } \\
\text { 9. Participacão do imposto na }\end{array}$ & 0,2 & 1,2 & 1,1 & 0,6 & 0,4 \\
\hline $\begin{array}{l}\text { receita total } \\
\text { 10.Participação da contribuiçāo }\end{array}$ & 25,5 & 26,4 & 28 , & 34,6 & 26,0 \\
\hline $\begin{array}{l}\text { associativa } \\
\text { 11.Participação da contribuição }\end{array}$ & 49,5 & 52,4 & 30,6 & 48,4 & 49,5 \\
\hline $\begin{array}{l}\text { assistencial } \\
\text { 12.Participação de outras receitas }\end{array}$ & $\begin{array}{l}12,0 \\
22,2\end{array}$ & $\begin{array}{l}12,9 \\
18,3\end{array}$ & $\begin{array}{l}25,9 \\
19,2\end{array}$ & $\begin{array}{l}16,3 \\
12,7\end{array}$ & $\begin{array}{l}12,7 \\
21,1\end{array}$ \\
\hline $\begin{array}{l}\text { 13.Porcentagem de associados } \\
\text { 14.Negociações realizadas por }\end{array}$ & 54,0 & 49,0 & 41,7 & 53,4 & 52,6 \\
\hline $\begin{array}{l}\text { sindicato (abs) } \\
\text { 15.Porcentagem de dissidios }\end{array}$ & 3,2 & 4,8 & 12,5 & 2,9 & 3,8 \\
\hline $\begin{array}{l}\text { sobre total } \\
\text { 16.Porcentagem de acordos na }\end{array}$ & 28,9 & 28,2 & 31,7 & 29 , & 28,8 \\
\hline $\begin{array}{l}\text { JT sobre total } \\
\text { 17.Porcentagem de sentencas }\end{array}$ & 13,6 & 15,9 & 15,6 & 17,3 & 14,3 \\
\hline sobre total & 2,9 & 4,9 & 1,5 & 2,8 & 3,3 \\
\hline $\mathrm{N}$ & 5.581 & 1.506 & 212 & 161 & 7.460 \\
\hline
\end{tabular}

Fonte: Pesquisa sindical IBGE - 1991, Tabulações especiais 
a CUT e a Força Sindical. Primeiro, não há dúvidas a respeito do caráter nacional da CUT e do caráter regional da Força Sindical. Em segundo lugar, a diferença de idade entre os sindicatos de uma e outra central é significativa. A CUT é uma central jovem, em boa medida composta por sindicatos criados sob seu comando, enquanto a Força Sindical já nasceu com peso não desprezível da história pré-transição, na verdade dos sindicatos pré-1968. Em terceiro lugar, é incontestável, também, que a CUT conseguiu estabelecer-se na vasta malha sindical brasileira, espelhando muito proximamente o universo dos sindicatos existentes. $O$ mesmo não pode ser dito sobre a Força Sindical. Finalmente, os sindicatos da CUT se financiavam principalmente por contribuições voluntárias, enquanto os da Força Sindical dependiam mais da contribuição assistencial e do imposto sindical. Esses são perfis bastante divergentes, que surpreendentemente redundam em formas convergentes de ação negocial, expressa no recurso equivalente à JT como mecanismo de solução do conflito trabalhista. O que importa marcar, porém, é que esse recurso era minoritário em relação ao total das negociações. Perto de $70 \%$ dos encontros entre capital e trabalho se davam por fora da JT nos sindicatos de ambas as centrais.

Esses achados permitem estruturar algumas expectativas em relação aos dados do survey, tendo em conta a intensidade da penetração das centrais em suas bases. Mais antiga e presente no cenário sindical, é de se esperar que a CUT tenha maior capacidade de estruturação de atitudes e práticas do que a Força Sindical. Do mesmo modo, seu discurso reformador, mais intenso e consistente, ensejará, supõe-se, atitudes mais ou menos favoráveis, mas nunca indiferentes por parte dos que representa e dos adversários. Em suma, aos perfis diferentes (em que pesem as similaridades) encontrados espera-se alguma contraparte na intensidade da penetração de cada central. Resta saber em que medida tal penetração, presumivelmente diferencial, redundará ou não em prospectos para a democracia tal como definidos na seção anterior. Vejamos

\section{O SURVEY}

Uma das hipóteses secundárias desse trabalho, orientadora da pesquisa centrada em categorias profissionais e não no universo de trabalhadores, era a de que, uma vez que as centrais sindicais não têm poder de contratação pelo trabalho, era de se supor que a preferência por elas estivesse filtrada, de alguma maneira, pelos sindicatos, isto é, a preferência por esta ou aquela central não estaria difusamente distribuída entre as categorias profissionais. Muito ao contrário, pertencer a esta ou aquela cate- 
goria significaria pertencer a ambientes profissional, institucional e ideológico razoavelmente estruturados onde o elemento central de constituição de identidades coletivas seria a relação com o sindicato. Logo, quanto mais intensa a presença sindical junto às bases de sustentação, e quanto mais esse sindicato fosse portador ou estruturador do discurso dessa ou daquela central, maior seria o poder discriminador da preferência pelas centrais nas atitudes e práticas dos trabalhadores dessas categorias. Foi por essa razão que escolhemos sindicatos representativos de cada central, na verdade os sindicatos que davam maior sustentação a elas. Foi por isso também que escolhemos um sindicato "fraco", isto é, com baixa presença junto aos representados. O survey foi realizado, então, junto a quatro categorias de trabalhadores: metalúrgicos de São Paulo (Força Sindical), metalúrgicos de São Bernardo e Diadema (aqui tratados como metalúrgicos do $\mathrm{ABC}$, da CUT), Trabalhadores em indústrias de alimentação de São Paulo (Força Sindical) e bancários de São Paulo (CUT). O sindicato dos trabalhadores em alimentação cumpriria a função de controle empírico da veracidade da hipótese secundária de pesquisa, pois se contrapunha a três outros sindicatos fortemente organizados, com altas taxas de sindicalização e de ação grevista ${ }^{10}$.

A preferência pelas centrais sindicais foi apreendida através de perguntas que procuravam medir: o grau de conhecimento dos entrevistados em relação a elas; a preferência propriamente dita; e a avaliação de sua atuação. Essas perguntas não estavam encadeadas no questionário. A primeira foi uma pergunta aberta, pedindo para o entrevistado nomear as centrais existentes. A segunda pergutava se ele sabia a que central seu sindicato estava filiado. Essas eram questões de informação. A terceira, utilizada como indicador de preferência na análise que se segue, era a seguinte:

"Se houvesse uma eleição para decidir hoje a filiação de seu sindicato a uma central sindical, qual delas você escolheria? (Resposta espontânea)"11.

${ }^{10}$ É preciso acrescentar entre as razões da escolha dessas categorias a sua posição estratégica na composição de poder da CUT e da Força Sindical e a diversidade dos setores econômicos de origem. Ademais, a seleção destas categorias permite comparar atitudes e opiniōes de trabalhadores de uma mesma categoria representados por sindicatos ligados a centrais sindicais diferentes; de categorias diferentes, mas representados por sindicatos ligados a uma mesma central; empregados na indústria e nos serviços e, por fim, com níveis de organização distintos.

11 Uma quarta questão pedia para o entrevistado comparar a CUT e a Força Sindical e dizer qual das duas têm obtido maiores ganhos para os trabalhadores. Em seguida, pedia-se para ele indicar o grau de influência das centrais em alguns assuntos pertinentes, como o problema do aposentado, a política salarial, educação e saúde etc. Finalmente, o entrevistado era instado a dar uma nota para a atuação da CUT e da Força Sindical. Essas três últimas, pois, eram medidas de avaliação. 
A distribuição das preferências pelas centrais segundo as categorias profissionais aparece na Tabela 3. Tomando-se o total da amostra (última coluna da tabela), a CUT é de longe a central mais preferida pelos entrevistados: $41 \%$ deles a escolheriam para filiação. Os que não sabem que central escolher aparecem em segundo lugar, com $30 \%$ dos casos. Em seguida aparece a preferência por nenhuma central em particular, com pouco mais de $13 \%$, a preferência pela Força Sindical, com $8,5 \%$ e, finalmente, a preferência por alguma das CGT's, com 3,8\%. É bastante significativo que mais de $40 \%$ dos entrevistados não tenham preferência por qualquer das centrais existentes ou simplesmente não tenham sabido responder à questão. A não preferência por quaisquer das centrais e a não resposta à questão, como veremos, são poderosos fatores de discriminação das atitudes e comportamentos dos entrevistados.

TABELA 3 - Preferência por centrais sindiais segundo as categorias profissionais

\begin{tabular}{|c|c|c|c|c|c|c|}
\hline \multirow{2}{*}{$\begin{array}{l}\text { Central que esco- } \\
\text { lheria p/ filiação }\end{array}$} & \multicolumn{4}{|c|}{ Categorias } & \multicolumn{2}{|c|}{ Totais } \\
\hline & $\begin{array}{c}\text { Met. } \\
\text { São Paulo }\end{array}$ & Met. ABC & Alimentaçāo & Bancários & $N$ & $\%$ \\
\hline CUT & 23,0 & 64,6 & 27,3 & 48,8 & 650 & 40,8 \\
\hline CGT & 4,8 & 2,3 & 4,5 & 3,5 & 60 & 3,8 \\
\hline Força Sindical & 22,5 & 2,0 & 6,3 & 3,3 & 136 & 8,5 \\
\hline Nenhuma & 16,3 & 9,4 & 13,3 & 14,8 & 214 & 13,4 \\
\hline Nao Sabe & 27,8 & 19,3 & 44,8 & 26,8 & 473 & 29,7 \\
\hline Outras Respostas & 5,8 & 2,3 & 4,0 & 3,0 & 60 & 3,8 \\
\hline TOTAL & 100,0 & 100,0 & 100,0 & 100,0 & 1593 & 100,0 \\
\hline $\mathrm{N}$ & 400 & 393 & 400 & 400 & 1593 & \\
\hline
\end{tabular}

Essa distribuição obriga-nos a um agrupamento das preferências pela Força Sindical e pelas CGTs numa única central, em face do pequeno número de referências a estas últimas em todas as categorias exceto os metalúrgicos de São Paulo. Mantê-las separado inviabilizaria análises estatisticamente mais sofisticadas em face do pequeno número de casos. Tal junção, porém, embora indesejada, pois seria importante manter a especificidade de cada central sindical, não é de todo artificiosa, dada a proximidade programática da Força com as duas CGT's, principalmente nos anos 1990. Na verdade, como mostram Martins Rodrigues e Cardoso (1993), a Força Sindical deve muito de seus adeptos a essas duas centrais. 


\section{ATITUDES E PRÁTICAS POLÍTICAS}

Isso posto, vejamos como cada central estrutura o ambiente onde atua. Iniciaremos a análise pelo impacto das centrais sindicais, ou melhor, da preferência por elas, sobre atitudes e práticas políticas dos trabalhadores segundo as categorias profissionais, orientados por duas hipóteses: primeiro, que preferir uma central faz diferença, isto é, atitudes e práticas dos que preferem são diferentes daquelas dos que não preferem ou não sabem que central escolheriam. Em segundo lugar, que preferir a CUT ou a Força Sindical tem consequências diversas, isto é, elas estruturam de forma diversa o ambiente onde atuam. Como pano de fundo sempre presente está a hipótese mais geral sobre a renovação do horizonte das relações de classe no Brasil, e trata-se de desvelar empiricamente (se houver) a qualidade das diferenças hipotetizadas ${ }^{12}$.

Analisando a Tabela 4, fica claro desde logo que, em todas as categorias, preferir alguma central é indicador decisivo de disposições mais inclusivas no sistema político. Isso é verdade até mesmo para os trabalhadores em alimentação, se bem que menos intensamente do que nas outras três categorias. Fica claro também que, de uma maneira geral, a preferência por uma ou outra central em particular discrimina mais fortemente naquelas categorias cujos sindicatos estão filiados a uma ou outra. Precisemos melhor esses achados.

Assim, é verdade que a preferência pela CUT torna todos os indicadores atitudinais estatisticamente significativos em todas as categorias, isto é, preferir a CUT indica consistentemente preferências mais intensas em relação ao mundo da política, incluindo-se aí a participação ${ }^{13}$. Numa formulação capaz de sintetizar o que os dados parecem estar revelando, a preferência pela CUT torna mais intensas as preferências "progressistas" dos trabalhadores (já veremos o que isso quer dizer). É bom marcar que isto se dá de forma mais contundente entre os bancários de São Paulo e os metalúrgicos do $\mathrm{ABC}$, categorias de referência da CUT. Por outro lado, a preferência pela Força Sindical torna, de forma menos consistente do que a preferência pela

12 O recorte empírico feito aqui é muito seletivo em face da riqueza dos dados do survey. Obrigamo-nos a uma seleção tanto dos problemas a tratar quanto de sua comprovação empírica. Por isso, o leitor interessado nos procedimentos estatísticos e nas comprovações empíricas mais extensas deve recorrer a Oliveira e Prandi coords (1996).

13 O teste de significância estatística (teste de F) foi feito comparando-se a média de cada central com a média global da amostra, para cada categoria em cada indicador, excluída a da central testada. Essa é uma medida direta de significância da diferença nas médias e é o único instrumento descritivo utilizado aqui. O ideal, obviamente, seria um tratamento das distribuiçōes de cada variável, procedimento inviabilizado num artigo como esse. 
CUT (porque as diferenças nem șempre são elevadas ou estatisticamente significativas), mais fortes as preferências "conservadoras" de todos os trabalhadores. Isso ocorre, em geral, mais intensamente entre os metalúrgicos de São Paulo e os trabalhadores em alimentação da mesma capital, se bem que, nesse último caso (a ser explorado mais tarde), as diferenças não sejam sempre significativas. Esse é um ponto que joga a favor de nosso argumento e voltaremos a ele. Vale ressaltar ainda que, na outra ponta do continuum denotado aqui, não saber que central escolheria para filiação torna ainda mais consistentemente "conservadoras" as preferências dos trabalhadores de todas as categorias, além de indicar fortemente "desalento político".

Para esclarecer esse achado, tomemos os índices de informação, de atitudes democráticas, de participação e de "political malaise "14 (ou desalento). Em conjunto, esses indicadores fornecem elementos poderosos para a mensuração do caráter progressista ou conservador das atitudes dos trabalhadores segundo a preferência por centrais sindicais. $O$ índice de informação deve ser tomado aqui como uma medida da sofisticação cognitiva dos entrevistados. Esse índice está fortemente correlacionado com a sofisticação de respostas a perguntas abertas sobre o significado de socialismo, de democracia, de privatização e sobre o golpe de 1964 . Além disso, ele está correlacionado com praticamente todos os indicadores atitudinais e comportamentais dos entrevistados. Já o índice de atitudes democráticas agrega vários indicadores de aceitação da institucionalidade democrática (como partidos, congresso nacional, eleições, voto universal, etc.) e da própria democracia como sistema de governo. O índice de participação mede intensidade de participação na vida pública (desde greves até a relação com o partido de preferência). Finalmente, o índice de "political malaise" mede a tendência a sentir-se excluído ou não representado pelo sistema político e sindical. Ao contrário dos demais, pois, quanto menor o índice, mais inclusivas as atitudes do entrevistado.

Iniciando pelo índice de informação, fica claro que preferir uma central tem impacto poderoso sobre sua distribuição. Os que não sabem a que central se filiariam são, com exceção dos bancários, cerca de dois terços $(2 / 3)$ menos informados do que os que preferem a central à qual seu sindicato está filiado ${ }^{15}$. Mesmo entre os bancários, categoria com índices

${ }^{14}$ Esse conceito aparece pela primeira vez em Dahl (1971), e descreve uma situação em que a população não se sente representada no sistema político, que the aparece como distante, inacessível, orientando atitudes de descrença em relação às instituições e aos canais de participação política.

${ }^{15} \mathrm{Na}$ verdade, $75 \%$ dos que dizem não saber que central escolheriam não conhecem as centrais sindicais. Além disso, 89\% deles não sabem a que central seu sindicato está filiado. Logo, são efetivamente trabalhadores desinformados. 
sempre maiores de informação, a diferença nas médias chega quase à metade. Em segundo lugar, os trabalhadores tendem a ser mais informados segundo a central preferida nas categorias de base de cada central. Assim, os metalúrgicos de São Paulo e os trabalhadores em alimentação que preferem a Força Sindical são mais bem informados que os demais, o mesmo ocorrendo entre os metalúrgicos do $\mathrm{ABC}$ que preferem a CUT. Com os bancários isso não é tão verdadeiro: os que preferem a Força Sindical são ligeiramente melhor informados, em média, do que os que preferem a CUT, mas os bancários são mais informados em geral, retirando muito do peso estatístico dessa ocorrência.

Mas é na análise dos índices de atitudes democráticas (que pode variar de 0 a 10) e de "political malaise" (que varia de 0 a 6) que o ponto em questão se torna mais evidente. Os trabalhadores que preferem a CUT estão consistentemente mais propensos a aceitar a institucionalidade democrática do que os demais, não importa qual a categoria. Aqui, inclusive, o padrão verificado em relação aos indicadores anteriores é rompido: preferir uma central nem sempre é condição suficiente para aumentar a propensão democrática dos trabalhadores. É o caso dos metalúrgicos do $\mathrm{ABC}$ e dos bancários de São Paulo que preferem a Força Sindical, menos democraticamente orientados do que os que não preferem qualquer central e do que os que não sabem. No mesmo diapasão, sentir-se alijado ou distante do mundo da política é atitude tanto mais intensa quanto menos se tenha preferência por alguma central e, com exceção dos trabalhadores em alimentação, preferir a CUT é indicador consistente de menor sentimento de desalento político do que preferir a Força Sindical. Por outro lado, não saber que central escolheria para filiação amplia consideravelmente o grau de desalento, isto é, o sentir-se alijado da política. Já no que se refere à participação, ela é consistentemente maior entre os cutistas e os forcistas do que entre os demais, mas os que preferem a CUT participam mais intensamente da vida pública do que os que preferem a Força Sindical.

Embora as diferenças de médias não pareçam muito intensas no caso do índice de desalento político, a proximidade esconde diversidades de monta que merecem ser marcadas. A Tabela 4 não mostra, mas entre os trabalhadores que preferem a CUT, por exemplo, $58 \%$ dos metalúrgicos de São Paulo atingem índice igual ou inferior a 3 (numa escala que varia de 0 a 6, onde 0 corresponde ao menor índice de desalento e 6, ao maior); $68 \%$ dos metalúrgicos do $\mathrm{ABC}$ atingem o mesmo índice; $58 \%$ dos trabalhadores em alimentação; e $83 \%$ dos bancários. Por outros termos, preferir a CUT coloca mais da metade dos trabalhadores na metade inferior da distribuição do índice. Alternativamente, entre os trabalhadores que não sabem que central escolheriam para filiação, esses valores se invertem con- 
TABELA 4 - Médias de alguns indicadores selecionados segundo a preferência por centrais sindicais, por categoria profissional

\begin{tabular}{|c|c|c|c|c|c|c|c|}
\hline \multirow[b]{3}{*}{ Categorias } & \multicolumn{6}{|c|}{ Indicadores selecionados } & \multirow{3}{*}{$\frac{N}{1533}$} \\
\hline & \multirow{2}{*}{$\begin{array}{l}\begin{array}{l}\text { Central de } \\
\text { preferência }\end{array} \\
\text { Total } \\
\end{array}$} & \multicolumn{5}{|c|}{$\begin{array}{l}\text { Índ. de Índ. de Ind. de atit. Índ. de "pol. Fator de } \\
\text { inform. particip. democrát. malaise" } \\
\text { politizaç. }\end{array}$} & \\
\hline & & 9,38 & 2,21 & 5,4 & 3,0 & 0,03 & \\
\hline $\begin{array}{l}\text { Metalúrgicos } \\
\text { de São Paulo }\end{array}$ & $\begin{array}{l}\text { CUT } \\
\text { FS/CGT } \\
\text { Nenhuma } \\
\text { Não sabe }\end{array}$ & $\begin{array}{r}\left(^{*}\right) 11,2 \\
\left(^{*}\right) 12,4 \\
8,18 \\
\left(^{*}\right) 4,79\end{array}$ & $\begin{array}{r}\text { (*) }^{*}, 87 \\
2,39 \\
\left({ }^{*}\right) 1,92 \\
\text { (*) }^{*} 1,96\end{array}$ & $\begin{array}{r}\left(^{\star}\right) 5,64 \\
5,18 \\
\left(^{\star}\right) 4,43 \\
4,98\end{array}$ & $\begin{array}{r}\left(^{\star}\right) 3,03 \\
3,47 \\
3,6 \\
3,65\end{array}$ & $\begin{array}{r}\left({ }^{*}\right) 0,33 \\
\left({ }^{*}\right)-0,05 \\
-0,42 \\
\left(^{*}\right)-0,79\end{array}$ & $\begin{array}{r}92 \\
109 \\
65 \\
111\end{array}$ \\
\hline $\begin{array}{l}\text { Metalúrg. } \\
\text { do } A B C\end{array}$ & $\begin{array}{l}\text { CUT } \\
\text { FS/CGT } \\
\text { Nenhuma } \\
\text { Nāo sabe }\end{array}$ & $\begin{array}{r}\left(^{*}\right) 13,2 \\
10,6 \\
9,41 \\
\left(^{*}\right) 4,75\end{array}$ & $\begin{array}{r}\left(^{*}\right) 2,82 \\
2,65 \\
\left({ }^{*}\right) 1,89 \\
\left(^{*}\right) 2,04\end{array}$ & $\begin{array}{r}\left(^{\star}\right) 5,82 \\
\left(^{\star \star}\right) 4,41 \\
5,03 \\
\left(^{\star}\right) 4,78\end{array}$ & $\begin{array}{r}\left({ }^{*}\right) 2,65 \\
3,47 \\
2,92 \\
\left(^{\star}\right) 3,63\end{array}$ & $\begin{array}{r}\left(^{\star}\right) 0,4 \\
-0,34 \\
-0,16 \\
\left({ }^{*}\right)-0,84\end{array}$ & $\begin{array}{l}25 \\
17 \\
37 \\
76\end{array}$ \\
\hline $\begin{array}{l}\text { Trabalhado- } \\
\text { resemali- } \\
\text { mentação }\end{array}$ & $\begin{array}{l}\text { CUT } \\
\text { FS/CGT } \\
\text { Nenhuma } \\
\text { Não sabe }\end{array}$ & $\begin{array}{r}\left(^{*}\right) 9,36 \\
\left(^{*}\right) 10,7 \\
7,62 \\
\left(^{*}\right) 3,33\end{array}$ & $\begin{array}{r}(\star \star) \\
2,17 \\
2,07 \\
1,91 \\
\left({ }^{\star}\right) 1,81\end{array}$ & $\begin{array}{r}\left(^{*}\right) 5,43 \\
5,09 \\
4,91 \\
\left(^{*}\right) 4,58 \\
\end{array}$ & $\begin{array}{r}3,14 \\
3,0 \\
3,36 \\
(* *) 3,5 \\
\end{array}$ & $\begin{array}{r}\left({ }^{*}\right) 0,14 \\
\left({ }^{*}\right)-0,1 \\
-0,24 \\
\left(^{*}\right)-0,90\end{array}$ & $\begin{array}{r}109 \\
43 \\
53 \\
179 \\
\end{array}$ \\
\hline Bancários & $\begin{array}{l}\text { CUT } \\
\text { FS/CGT } \\
\text { Nenhuma } \\
\text { Não sabe }\end{array}$ & $\begin{array}{r}\left(^{*}\right) 12,6 \\
\left(^{*}\right) 13,1 \\
10,9 \\
\left(^{*}\right) 6,8\end{array}$ & $\begin{array}{r}\text { (*)}^{*} 2,29 \\
\text { (*) }^{*} 1,59 \\
1,97 \\
\text { (*) }^{*} 1,74\end{array}$ & $\begin{array}{r}\left({ }^{\star}\right) 6,57 \\
5,52 \\
\left(^{\star *}\right) 5,56 \\
\left({ }^{*}\right) 5,63\end{array}$ & $\begin{array}{r}\left({ }^{\star}\right) 2,07 \\
2,41 \\
\left(^{* *}\right) 2,86 \\
(* *) 2,83\end{array}$ & $\begin{array}{r}\left(^{\star}\right) 1,00 \\
0,63 \\
0,54 \\
\left(^{\star}\right) 0,09\end{array}$ & $\begin{array}{r}195 \\
27 \\
59 \\
107\end{array}$ \\
\hline
\end{tabular}

(*) Significativos pelo menos no nivel 0,01

(**) Significativos pelo menos no nivel 0,05

sistentemente: encontraremos $57 \%$ deles com índice igual ou superior a 4 entre os metalúrgicos de São Paulo; $58 \%$ dos metalúrgicos do $\mathrm{ABC}$ que não sabem também têm índice igual ou superior a $4 ; 53 \%$ entre os trabalhadores em alimentação; e 34\% entre os bancários. Com exceção desses últimos, pois, não preferir uma central joga mais da metade dos trabalhadores para a metade superior da distribuição do índice, ou a metade que indica maior desalento político.

Esses indicadores (com exceção da participação) estão sintetizados em algo que denominamos "fator de politização". Fruto de análise fatorial, essa variável agrupa os seguintes indicadores: interesse por política (nenhum, algum ou muito), índice de informação, índice de "political malaise", índice de atitudes democráticas, escolaridade e quantas vezes por semana o entrevistado costuma ler sobre política. Supomos que há um fator subjacente a todos esses indicadores, que é justamente o fator de politização. Aqueles que se encontram no topo superior do índice são muito informados, escolari- 
zados, se interessam por política e valorizam intensamente a institucionalidade democrática. Os encontráveis na ponta inferior do índice (ou fator) são o oposto disso ${ }^{16}$. A intenção aqui foi criar um instrumento mais robusto, capaz de revelar de forma sintética o que as variáveis isoladas parecem indicar.

Fica claro: 1. que os bancários são mais politizados do que os demais; 2 . que preferir uma central ${ }^{17}$ aumenta consideravelmente a chance do trabalhador ser mais politizado; $\mathrm{e} 3$. que não saber a que central se filiar reduz dramaticamente a politização dos trabalhadores. É evidente também que preferir a CUT aumenta consideravelmente o grau de politização dos entrevistados em todas as categorias, e mais fortemente entre os metalúrgicos do $\mathrm{ABC}$ e os bancários da capital. A preferência pela Força Sindical faz o mesmo em suas categorias de referência, mas com menor intensidade.

Para que se tenha uma melhor apreensão do que esses dados significam, é importante avaliar, ainda que sinteticamente, a distribuição percentual (e não apenas média) do fator de politização segundo a preferência por uma central e segundo as categorias. Não temos espaço para reproduzir uma larga tabela da distribuição por decis, assim resumimos seus resultados: a preferência pela CUT joga metade dos metalúrgicos de São Paulo e dos trabalhadores em alimentação, por exemplo, para o topo da distribuição do fator de politização nessas populações específicas: a mediana encontrada recai no $8 \underline{0}$ e no $7 \underline{0}$ decis das distribuições, respectivamente. Por outras palavras, metade dos trabalhadores que preferem a CUT apresentam índice de politização equivalente aos 20 ou $30 \%$ mais politizados nessas categorias específicas (e aos 30 ou $40 \%$ mais politizados na amostra global, respectivamente). Já a mediana dos que preferem a Força Sindical nessas mesmas categorias recai no $7 \underline{0}$ decil entre os metalúrgicos e no $8 \underline{0}$ decil entre os trabalhadores em alimentação, isto é, preferir a Força Sindical também tem impactos sobre o grau de politização dos metalúrgicos e dos trabalhadores em alimentação paulistanos. É central reter, ademais, que não saber que central escolher lança os trabalhadores à base do fator de politização tanto de suas categorias específicas quanto do total das amostras: metade dos metalúrgicos de São Paulo que não sabe a central que escolheria está entre os $25 \%$ menos politizados nessa catagoria e também na amostra global, enquanto metade dos trabalhadores em indústrias alimentícias recai entre os $35 \%$ menos politizados dessa categoria e entre os $25 \%$ menos politizados da amostra total. Esse movimento

16 Os procedimentos técnicos adotados na construção desse fator devem ser buscados em Oliveira e Prandi coords (1996), anexo estatístico. Aqui, é importante salientar que o fator, sozinho, dá conta de $49 \%$ da variância das variáveis que o compõem.

17 Se bem que isso ocorra também entre os bancários. Mas o número de casos (27) é muito pequeno para sustentar conclusões peremptorias. 
mais geral se repete, ponto por ponto, para os trabalhadores nos dois sindicatos da CUT. Aqui, porém, a preferência pela Força Sindical indica menor grau de politização dos metalúrgicos do $A B C$, na verdade lançando metade deles ao nível dos $20 \%$ menos politizados na amostra específica e ao dos $30 \%$ menos politizados na amostra global. Entre os bancários isso não ocorre, já que os que preferem a CUT e a Força Sindical estão no mesmo decil (70). Nos dois casos, porém, não preferir uma central indica baixo grau de politização (metade entre os $20 \%$ menos politizados no $\mathrm{ABC}$ e entre os $30 \%$ menos entre os bancários).

Não resta dúvidas, pois: preferir uma central é indicador poderoso do grau de politização dos trabalhadores. Mais do que isso: a preferência pela CUT está intensamente associada àquele grau de politização, em todas as categorias profissionais. A preferência pela Força Sindical está associada com maior politização apenas nas categorias de referência dessa central , confirmando que a CUT estrutura de forma mais intensa o horizonte das preferências políticas dos trabalhadores, não importa se estes pertencem a sindicatos filiados a ela ou não. Essa afirmação é central para nós, e é bom retê-la. Ao mesmo tempo, é evidente que não saber a central que o trabalhador escolheria para filiação indica fortemente baixo grau de politização.

É preciso deixar claro que o interesse dessa discussão não é mostrar que os simpatizantes da CUT são mais progressistas ou politizados do que os simpatizantes da Força Sindical. O interesse é mostrar que a preferência por uma central realmente faz diferença; e que a preferência por uma ou outra central também faz diferença. O fator de politização revelou-se indicador poderoso dessa diferença, por isso foi esmiuçado aqui.

Em suma, as centrais sindicais têm poder estruturante sobre as atitudes políticas dos trabalhadores, principalmente seu grau de politização. Preferir uma central indica, de forma inconteste para todas as categorias (embora em menor intensidade entre os trabalhadores em alimentação), maior intensidade no sentimento de inclusão no sistema político e na disposição à participação na vida pública. Isso é ainda mais verdadeiro em relação à CUT, cuja manifestação de preferência coloca mais de $75 \%$ dos trabalhadores entre os $50 \%$ mais politizados. Os dados mostram claramente, ademais, que esses achados são mais intensos nas categorias de referência de cada central.

\section{ATITUDES E PRÁTICAS SINDICAIS}

A outra hipótese secundária desse trabalho, formulada em Cardoso (1992) e explorada mais tarde em Comin (1995), supõe que as centrais sindicais se consolidaram no Brasil como centros constituidores e reprodu- 
tores de identidades políticas, mais do que sindicais, dentre outras coisas porque o poder de contratação pelo trabalho é monopólio dos sindicatos. Isso canalisou a ação das centrais na direção do sistema político, seja através da definição de estratégias de ação e de programas mais ou menos bem delineados de intervenção, seja através da participação (ou a negação de participação, no caso da CUT) em tentativas de pactação social. Nesse quadro, é legítimo supor que as centrais estruturam mais fortemente as atitudes políticas do que as sindicais, o que delimita com maior precisão o caráter de sua atuação e a natureza da consolidação de seu poder na sociedade brasileira. É hora de verificar empiricamente esta hipótese.

O espaço disponível obriga-nos a uma abordagem muito sintética do problema. Desde logo é possível afirmar que a associação entre preferência por centrais e as atitudes e práticas sindicais é substancialmente menor do que a encontrada no caso das atitudes políticas, no seguinte sentido: nem sempre (segundo as categorias profissionais) preferir uma central qualquer será indicador de maior proximidade com o sindicato. Essa afirmação é crucial ao nosso argumento e precisa ser melhor qualificada. Isso será feito por meio de um exercício metodológico de redução de uma série de indicadores de atitudes e práticas sindicais a uma variável única. Tal redução se fará com base no fato de que parece plausível imaginar que quanto mais intensa a presença sindical na vida cotidiana de seus representados, maior a resposta desses últimos às demandas sindicais por participação e legitimidade. Isso tornaria metodologicamente plausível tratar como escalonáveis essas dimensões, encaradas como medidas de um substrato comum: a presença sindical no cotidiano das pessoas, ou a capacidade do sindicato nuclear as escolhas cotidianas de seus representados, inclusive a ação coletiva e a legitimação da ação sindical.

O questionário de origem do survey traz uma série de indicadores da intensidade da presença sindical junto à sua base capazes de compor tal índice. Uma bateria de perguntas se refere a vários mecanismos de acesso à informação sobre o sindicato (jornais e boletins, visita ao sindicato, conversa com colegas, murais na empresa, representantes ou delegados sindicais e matérias pagas na imprensa, num total de seis mecanismos de informação). Conexa a esta está a pergunta sobre a existência ou não de representantes sindicais no local de trabalho. Há ainda dois indicadores de informação: o fato do trabalhador ser capaz de nomear corretamente pelo menos um dirigente sindical; e de conhecer a central a que seu sindicato está filiado. A essas questões juntaremos a participação em greves, em assembléias, a nota para o sindicato, e as opiniões em relação à ação e à estratégia do sindicato, isto é, se o trabalhador acha que o sindicato contribui ou atrapalha na solução dos problemas da categoria, e se ele acha eficiente ou não a estratégia de ação sindical. 
Chega-se com isso a um "índice de proximidade com o sindicato", que pode variar de 0 a 14. Para atingir o índice 14 , o trabalhador tem que dar nota igual ou maior que 7 ao sindicato, achar que ele contribui para a solução dos problemas da categoria, julgar eficiente sua estratégia de ação, ter acesso a todos os seis mecanismos de informação sobre o sindicato à sua disposição, ter representante sindical no local de trabalho, conhecer pelo menos um dirigente sindical, conhecer a que central seu sindicato está filiado, participar de greves e de assembléias. Nesses termos, um trabalhador com índice 0 (zero) deve ser considerado como intensamente arredio ou indiferente à atividade representativa sindical, porque não se demonstrou disposto a qualquer relação com sua entidade. Um trabalhador com índice 14 deve ser considerado como intensamente permeável à mesma atividade representativa, tendo na relação com o sindicato, talvez, o momento mais importante de sua biografia ${ }^{18}$. Trata-se de medida abrangente, com grande poder discriminante sobre as preferências dos trabalhadores e, na verdade, funciona como uma medida de inclusão tanto quanto os indicadores de atitudes e práticas políticas, pois sua correlação (pearson) é superior a 0,40 com o fator de politização e com a intensidade da preferência partidária, por exemplo.

Desse ponto de vista, chama a atenção o fato de que os menores índices de proximidade são encontrados (com exceção dos metalúrgicos da capital paulista) entre os que não sabem que central escolher (Tabela 5). Por outras palavras, não saber que central escolher, além de indicar desalento político, indica também desalento sindical. Alternativamente, escolher uma central é indicador de inclusão política e também de inclusão sindical. Porém, e essa é a segunda constatação importante, com exceção dos metalúrgicos de São Paulo, a preferência pela CUT tem impacto positivo não desprezível sobre o índice geral de proximidade do trabalhador com seu sindicato, impacto nem de longe encontrado nos simpatizantes da Força Sindical. Por outros termos, os que preferem a CUT são consumidores mais intensos das atividades sindicais do que os demais, e devem ser

18 O Alpha de Crombach, que é uma medida de aditividade das variáveis numa escala, é de .80 para toda a amostra, variando de 0,76 entre os trabalhadores em alimentação e 0,82 entre os metalúrgicos do ABC. Segundo os manuais de estatística, para ser confiável (reliable) e válido, o Alpha deve ser igual ou maior do que 0,90 . Isso permitiria, por exemplo, que médicos classificassem a probabilidade do câncer com alguma segurança, dados alguns indicadores identificados como escalonáveis. Nas ciências sociais essa precisāo é raramente necessária ou mesmo possível. Nosso objetivo aqui é apontar a direção, mais do que a intensidade precisa da associação entre a proximidade com o sindicato e a preferência por centrais. Para nossos propósitos, muito distantes da indução probabilística, o Alpha de 0,80 é alto o bastante para permitir análise estatística robusta. Ver, sobre a metodologia de criação desse índice, Oliveira e Prandi coords (1996). 
encarados como mais intensamente incluídos, no sentido de que se sentem representados na (e participam da) ação de seu sindicato. Mesmo entre os metalúrgicos da capital a preferência pela CUT é relevante e, entre os metalúrgicos do $\mathrm{ABC}$, a diferença em favor dos que preferem a CUT é muito alta (mais de 2/3).

TABELA 5 - Índice de proximidade com o sindicato segundo a preferência por centrais sindicais.

\begin{tabular}{|c|c|c|c|}
\hline \multirow[b]{2}{*}{ Preferência por centrais } & \multicolumn{2}{|c|}{$\begin{array}{l}\text { Medida da proximidade } \\
\text { com o sindicato }\end{array}$} & \multirow[b]{2}{*}{$N$} \\
\hline & Média & Desvio padrão & \\
\hline Metalúrgicos de São Paulo & 5,68 & 3,02 & 377 \\
\hline $\begin{array}{l}\text { CUT } \\
\text { FS/CGT } \\
\text { Nenhuma } \\
\text { Não sabe }\end{array}$ & $\begin{array}{l}6,29 \\
6,70 \\
4,26 \\
5,02\end{array}$ & $\begin{array}{l}3,05 \\
2,82 \\
2,84 \\
2,82\end{array}$ & $\begin{array}{l}92 \\
109 \\
65 \\
111\end{array}$ \\
\hline Metalürgicos do $A B C$ & 8,18 & 3,74 & 384 \\
\hline $\begin{array}{l}\text { CUT } \\
\text { FS/CGT } \\
\text { Nenhuma } \\
\text { Não sabe }\end{array}$ & $\begin{array}{l}9,74 \\
6,59 \\
5,11 \\
4,82\end{array}$ & $\begin{array}{l}3,12 \\
2,79 \\
2,90 \\
2,83\end{array}$ & $\begin{array}{l}254 \\
17 \\
37 \\
76\end{array}$ \\
\hline Alimentaçāo & 3,65 & 2,62 & 384 \\
\hline $\begin{array}{l}\text { CUT } \\
\text { FS/CGT } \\
\text { Nenhuma } \\
\text { Não sabe }\end{array}$ & $\begin{array}{l}4,61 \\
3,91 \\
3,47 \\
3,06 \\
\end{array}$ & $\begin{array}{l}2,81 \\
3,19 \\
2,40 \\
2,23 \\
\end{array}$ & $\begin{array}{l}109 \\
43 \\
53 \\
179 \\
\end{array}$ \\
\hline Bancários & 6,48 & 2,78 & 388 \\
\hline $\begin{array}{l}\text { CUT } \\
\text { FS/CGT } \\
\text { Nenhuma } \\
\text { Não sabe }\end{array}$ & $\begin{array}{l}7,58 \\
5,63 \\
5,41 \\
5,27\end{array}$ & $\begin{array}{l}2,80 \\
2,24 \\
2,23 \\
2,33 \\
\end{array}$ & $\begin{array}{l}195 \\
27 \\
59 \\
107\end{array}$ \\
\hline Total & 6,00 & 3,47 & 1533 \\
\hline
\end{tabular}

Em termos agregados, pois, a proximidade com o sindicato é discriminada pelas centrais sindicais. Na verdade, preferir a CUT indica inclusão, mas preferir a Força Sindical só traz esse resultado no caso dos metalúrgicos de São Paulo e, em parte, dos metalúrgicos do ABC. Logo, é preciso reconhecer que aquela discriminação se dá de forma bastante 
menos intensa do que no caso dos indicadores de atitudes políticas. Isso fica mais fortemente marcado no caso dos trabalhadores em alimentação. $\hat{E}$ entre eles que iremos encontrar os menores índices de proximidade com o sindicato e também os menores índices de politização. É entre eles, também, que o poder de discriminação das centrais sindicais é menos acentuado no caso das atitudes sindicais. Mas não podemos dizer o mesmo com respeito às atitudes políticas. Exploremos melhor esse ponto, porque o caso dos trabalhadores em alimentação ajuda a estruturar a análise do impacto geral das centrais sindicais sobre atitudes e práticas dos trabalhadores.

Os dados apresentados nesta seção e na anterior não devem deixar dúvidas: a preferência pelas centrais sindicais, mesmo numa categoria profissional de baixo índice de politização e de reduzido poder sindical como a dos trabalhadores em alimentação, tem relevância como discriminante das atitudes políticas. Se um trabalhador nessa categoria prefere uma central (a CUT um pouco mais intensamente do que a Força Sindical), ele será consistentemente mais democrata, terá relações mais estreitas com o partido preferido, será mais informado e mais politizado em geral. Mas isso não é tudo. Sabemos que o sindicato dos trabalhadores em alimentação é frágil. Tem número muito pequeno de filiados, a taxa de participação dos trabalhadores da base é inferior a todos os outros sindicatos analisados nesse trabalho, e a penetração do discurso sindical no ideário dos trabalhadores é bastante restrito. Isso fica muito evidente na distribuição do índice geral de proximidade que discutimos antes, que revela que o grau de proximidade com o sindicato, nessa categoria, é consistente e intensamente inferior às demais, inclusive os metalúrgicos de São Paulo.

Pois bem, é justamente esse aspecto que nos interessa marcar: ali onde o sindicato é pouco presente, o poder discriminante das centrais sindicais sobre atitudes e práticas sindicais é menor. Mais do que isso, comparando-se as quatro categorias, esse poder de fato declina, no agregado, quanto menos presente é o sindicato. As categorias analisadas aqui podem facilmente ser classificadas num continuum de proximidade com o sindicato que tem grande correspondência com o poder discriminante das centrais. Numa ponta estaria o sindicato dos metalúrgicos do $A B C$, seguido dos bancários, dos metalúrgicos e dos trabalhadores em alimentação da capital. Essa ordem é dada pela distribuição das médias do índice de proximidade com o sindicato para cada categoria em particular que aparecem na Tabela 5. É nessa ordem que encontraremos também a intensidade do poder discriminante da preferência por alguma central sobre atitudes e práticas sindicais. 
Dizendo de outro modo, e insistindo num ponto central aqui: os trabalhadores em alimentação são uma categoria em que o sindicato joga um papel residual na constituição das atitudes e práticas de seus representados ${ }^{19}$. Entretanto, vimos que preferir ou não uma central tem poder discriminante sobre suas atitudes e práticas políticas, e que preferir a CUT aumenta consideravelmente seu grau de politização. O mesmo não ocorre em relação às atitudes e práticas sindicais. Nesse caso, a preferência ou não por uma central tem impacto residual, quando tem. Por outras palavras, o sindicato com menor intensidade da presença sindical é também o sindicato com menor poder discriminante das centrais em relação às atitudes sindicais dos trabalhadores que representa. E o sindicato com maior presença sindical é também aquele em que as centrais, em especial a CUT, discrimina mais fortemente. Esse achado vem em direção da confirmação de duas hipóteses guia desse trabalho: que as centrais sindicais estruturam o ambiente onde atuam mediadas pela ação dos sindicatos; e, em conexão com o que se discutiu na seção anterior, que as centrais sindicais "gravitam", por assim dizer, no universo da política, mais do que (se bem que também) no universo da ação sindical. As atitudes e práticas sindicais estão determinadas, antes de tudo, pela intensidade da presença sindical na vida dos representados.

\section{ALGUMAS CONCLUSÕES}

Esse trabalho se organizou a partir de uma aposta normativa na democracia. A construção democrática implica, dentre outras coisas, na constituição de instituições capazes de canalizar, organizar e fazer valer o interesse dos agentes sociais. A consolidação dessas instituições, quanto mais inclusiva, mais legítima do ponto de vista de uma contratualidade que se quer construir, isto é, uma contratualidade em que os interesses divergentes possam encontrar e mesmo construir parâmetros de medida atentos à divergência mesma entre eles, divergência encarada como legítima em si mesma e nas partes (interesses) que a constituem. Não se trata apenas da legitimidade das regras do jogo democrático, portanto, mas da estabilização de uma atitude em relação a essas regras que tenha no horizonte e como meta irrecorrível a sua preservação contra investidas autoritárias de qualquer sorte. As instituições, quando democráticas, cumprem exatamente esse papel. Nossa intenção aqui foi avaliar a natureza da consolidação do poder das centrais sindicais no Brasil pós-autoritário por

\footnotetext{
19 Ver demonstração consistente desse ponto, uma vez mais, em Oliveira e Prandi coords.
} 
esse ângulo, fazendo um recorte muito preciso, isto é, atento à presença das centrais como elementos estruturadores do campo de atitudes e práticas políticas e sindicais daqueles que lhe servem de base social.

A análise confirmou um fato crucial: as centrais estruturam fortemente, ou indicam o sentido das atitudes políticas, mas não são os agentes primários da estruturação do ambiente sindical. $\mathrm{O}$ agente primário dessa estruturação são os sindicatos. É por intermédio destes, acessado pelo grau de proximidade com os que os sindicatos representam, que as centrais sindicais discriminam as atitudes e práticas sindicais: ali onde 0 sindicato é ausente ou fraco, ali também as centrais discriminam pouco ou nada; e ali onde o sindicato é presente ou forte, ali também as centrais discriminam mais intensamente. Não por outra razão, afirmar a ausência de preferência por uma central é indicador importante de que o trabalhador não se sente representado por seu sindicato, isto é, a não opção por qualquer central é indicador de exclusão da vida associativa. Em alguns casos, como o dos metalúrgicos de São Paulo, é indicador mais forte do que não saber que central escolher.

$\mathrm{O}$ caso dos trabalhadores em indústrias alimentícias torna-se paradigmático justamente porque sua proximidade com o sindicato é muito pequena. Se as centrais sindicais tivessem impacto independentemente dos sindicatos, seria de se esperar desses trabalhadores atitudes próximas dos metalúrgicos da capital, também filiados à Força Sindical. Mas isso ocorre apenas em parte, nomeadamente, nas atitudes e práticas políticas dos trabalhadores. No caso das atitudes e práticas sindicais, o sinal da relação entre elas e a preferência pelas centrais sindicais é o mesmo nas duas categorias (menor intensidade na relação com o sindicato), mas essa relação é muito menos intensa nos trabalhadores em alimentação. A contrapartida disso também é verdadeira, isto é, o caso dos metalúrgicos do $\mathrm{ABC}$ é paradigmático pela razão inversa: o sindicato é muito próximo da vida cotidiana dos trabalhadores. De nosso ponto de vista, isto significaria que as identidades políticas e sindicais dos indivíduos se estariam constituindo tendo na relação com o sindicato um momento importante, senão fundamental. Isso se confirma, pois é justamente nessa categoria que iremos encontrar o maior grau de influência da preferência por uma central (no caso, a CUT) nas atitudes e práticas sindicais e também nas práticas políticas. Isso permite formular a primeira conclusão, em quatro tempos:

1. no caso dos trabalhadores em alimentação, a preferência pelas centrais estaria funcionando como fator discriminante das atitudes e práticas políticas porque essa preferência seria uma dentre outras num espectro mais amplo de participação 
e de politização. Esse caso limite é essencial aqui, pois revela que as centrais sindicais gravitam consistentemente no universo da política, mais do que no universo sindical;

2. isso quer dizer que os trabalhadores não necessitam manter uma relação de proximidade com o sindicato para que a preferência por uma central sindical indique a direção de suas preferências políticas. Há certa autonomia entre as esferas de preferências e de práticas política e sindical de tal sorte que, mesmo entre trabalhadores onde o sindicato tem baixa penetração (alimentação), a preferência pelas centrais, principalmente a preferência pela CUT, tem poder real de discriminação das atitudes políticas;

3. é verdade que esse poder é consistentemente mais intenso nas categorias em que o sindicato é mais próximo dos trabalhadores. Os sindicatos realmente atuam como catalisadores e disseminadores de identidades coletivas, vertendo-se em instituições com capacidade efetiva de galvanizar lealdades e disposição para a ação. Desse ponto de vista, a preferência pelas centrais tem a eficácia de seu impacto nas atitudes e práticas aumentada quando filtrada pela ação sindical;

4. o caso dos trabalhadores em alimentação, uma vez mais, sugere que o poder discriminante da preferência pelas centrais nas atitudes e práticas sindicais, para ser efetivo, depende fortemente da mediação da ação sindical. Isso quer dizer simplesmente que o agente efetivo da identidade sindical é o sindicato, não as centrais sindicais.

Por outro lado, e essa é a segunda conclusão importante, os dados confirmam expectativas quanto ao poder estruturante das centrais sindicais sobre atitudes e práticas dos trabalhadores: preferir uma central sindical qualquer faz diferença; e preferir a CUT tem impactos diversos do que preferir a Força Sindical. Elas são, claramente, alternativas de organização de interesses dos trabalhadores, e o impacto diferencial de uma e outra nas atitudes e práticas políticas e sindicais sugere que elas estruturam, canalizam, organizam e vocalizam interesses diversos, instaurando uma clivagem real nos horizontes valorativo, motivacional, ideológico e prático dos trabalhadores que representam. É verdade que tal clivagem se deve fortemente à maior intensidade das preferências organizadas pela CUT, mas a preferência pela Força Sindical está longe de ser indiferente. Preferir a Força Sindical tem consequências efetivas em termos de inclusão política e sindical por oposição aos que não têm preferência ou não 
têm condições de preferir, porque são desinformados.

A terceira conclusão relevante é a de que a preferência por uma central é indicador poderoso de disposições mais inclusivas, isto é, preferir uma central indica, fortemente, propensão para a aceitação do jogo democrático; indica, fortemente, informação e politização; indica disposição para a participação na vida pública. Não temos elementos para afirmar que as centrais são canais efetivos de participação, já que não era esse o objetivo do survey e temos dúvidas se isso pode ser objeto desse tipo de metodologia. Mas não restam dúvidas que a preferência por elas indica uma mudança qualitativa nas disposições individuais num sentido favorável à institucionalidade democrática. Desse ponto de vista, as centrais sindicais, e principalmente a CUT, devem ser encaradas como instituições renovadoras do horizonte político e sindical dos trabalhadores, numa direção alvissareira quanto à consolidação de relações democráticas de classe. Isso se dá, não fosse por muitas outras coisas, pelo menos em razão do fato de que a preferência por uma delas, e principalmente a preferência pela CUT, indica atitudes fortemente inclusivas e de reduzido desalento político. As centrais sindicais, ou a preferência por elas, indicam inclusão, e é essa indicação que nos permite dizer que elas estão contribuindo para a renovação dos horinzontes das relações de classe no Brasil.

ADALBERTO M. CARDOSO é professor do IUPERJ.

ALVARO A. COMIN é pesquisador do CEBRAP.

\section{REFERÊNCIAS BIBLIOGRÁFICAS}

Boito Jr. Armando B. (1991): Sindicalismo de Estado no Brasil: análise crítica da estrutura sindical. São Paulo, Paz e Terra.

Dahl, Robert A. (1971): Polyarchy: Participation and opposition. New Haven, Yale University Press.

Cardoso, Adalberto M. (1992): "O pragmatismo impossível: origens da Força Sindical". Novos Estudos (32). São Paulo, Cebrap.

Cardoso, Adalberto M. (1995): Nas teias da modernidade - magmatismo sindical e democratização no Brasil. Tese de Doutorado, São Paulo, USP.

Cardoso, Adalberto M. coord. (1997): Para a reforma da estrutura sindical brasileira. Assessoria preparada para o Ministério do Trabalho. Rio/São Paulo, Iuperj/Cebrap (mimeo).

Cardoso, Adalberto M.; Lopes, A.; Comin, A. A.; e Piva, L. G. (1994): Perfil e opiniōes dos delegados ao V Congresso Nacional da CUT. São Paulo, Desep-CUT/Cebrap.

Cardoso, Adalberto e Comin, Alvaro A (1995): "Câmaras setoriais, modernização produtiva e democratização nas relaçōes entre capital e trabalho no Brasil". In: Castro, Nadya (org). A máquina e o equilibrista: tecnologia e trabalho na indústria automobilística brasileira. Sāo Paulo, Paz e Terra, 1995, pp. 387-427 
Comin, Alvaro A. (1994) "A experiência de formaçāo das centrais sindicais no Brasil". In: Oliveira, C. A. (org.): $O$ mundo do trabalho: crise e mudança no final do século. São Paulo, Scritta.

Comin, Alvaro A. (1995): A estrutura sindical corporativa: um obstáculo à consolidação das centrais sindicais. Dissertação de Mestrado em Sociologia, São Paulo, USP.

Douglas, Mary (1979): How institutions think. Syracuse, Syracuse University Press.

Martins Rodrigues, Leôncio (1989): Partidos e sindicatos: estudos de sociologia política. São Paulo, Ática.

Martins Rodrigues, Leôncio (1990): CUT: os militantes e a ideologia. São Paulo, Paz e Terra.

Martins Rodrigues, Leôncio (1991): “As tendências políticas na formação das centrais sindicais" in Boito Jr, Armando org (1991): O sindicalismo brasileiro nos anos oitenta. São Paulo, Paz e Terra.

Martins Rodrigues, Leôncio e Cardoso, Adalberto M. (1993): Força Sindical: uma análise sócio-políitca. Sāo Paulo, Paz e Terra.

Noronha, Eduardo (1992): Greves na transição brasileira. Dissertação de Mestrado em Ciência Política, Unicamp, (mimeo).

Oliveira, Francisco de e Prandi, J. Reginando coords (1996): Padrões de representação sindical e democracia no Brasil: un survey entre trabalhadores. Relatorio de final de pesquisa enviado à Fapesp. São Paulo, Cebrap*(mimeo).

Pochmann, Márcio (1996): "Mudança e continuidade na organização sindical brasileira no período recente". in Oliveira e Mattoso orgs. (1996: 269-301).

Rodrigues, Iram J. (1990): Comissão de fábrica e trabalhadores na indústria. São Paulo, Cortez/FASE.

Rodrigues, Iram J. (1996): "Perspectivas do sindicalismo no Brasil: o caso da CUT" in Diniz, Eli; Lopes, José S. e Prandi, J. Reginaldo (1996): O Brasil no rastro da crise. São Paulo/Rio de Janeiro, Anpocs/Hucitec/Ipea.

Santos, Wanderley Guilherme dos (1979): Cidadania e justiça - a política social na ordem brasileira. Rio de Janeiro, Campus.

Tavares de Almeida, M.H. (1983): "O sindicalismo brasileiro entre a conservação e a mudança". in Tavares de Almeida e Sorj, Bernardo: Sociedade e política no Brasil pós-64. São Paulo, Brasiliense.

Tavares de Almeida, M.H. (1988): "Difícil caminho: sindicatos e política na construção da democracia". in Reis \& O'Donnell (1988).

Tavares de Almeida, M.H (1992): Crise Econômica e Organizaçāo de Interesses: Estratégias do sindicalismo brasileiro nos anos 80 . Tese de Livre Docência em Ciência Política, USP, 1992, 178 pp. 


\title{
CENTRAIS SINDICAIS E ATITUDES DEMOCRÁTICAS
}

\author{
ADALBERTO M. CARDOSO \\ ALVARO A. COMIN
}

Mediante a análise de um survey realizado em São Paulo os autores examinam a representatividade das centrais sindicais perante os membros de sindicatos filiados. O foco da análise é dado pela questão da capacidade das centrais sindicais de efetivamente atingir suas bases e de converter seus discursos e suas práticas em fatores de constituição de identidades nos planos 
sindical e político. A resposta inicial é positiva: esse poder existe. A análise mais detida demonstra diferenças significativas entre as centrais sindicais, tanto no que diz respeito às atitudes e práticas políticas dos integrantes de sindicatos filiados quanto no tocante às atitudes e práticas sindicais.

\section{TRADE UNION CONFEDERATIONS AND DEMOCRATIC ATTITUDES}

Through the analysis of a survey conducted in São Paulo the authors examine the representativity of the Brazilian trade union confederations towards the members of affiliated unions. The focus of analysis is given by the question of the capability of the union centrals of effectively reaching their rank and file and of turning their discourses and practices into elements for the constitution of identities on the union and political levels. The initial answer is positive: there is such a power. Further analysis reveals significant differences between trade union confederations concerning both political and unionist attitudes and practices. 